\title{
EFEITO DA ÉPOCA DE COLHEITA, IRRIGAÇÃO E PERMANÊNCIA DE SEMENTES EM SOLO SECO NO DESENVOLVIMENTO INICIAL DE PLÂNTULAS DE Syngonanthus elegans (Bong.) Ruhland ${ }^{1}$
}

\author{
UBIRAJARA RUSSI NUNES ${ }^{2}$, SILVIA CRISTINA PASLAUSKI NUNES ${ }^{3}$, PATRÍCIA GOMES FONSECA ${ }^{3}$, \\ ROGÉRIO GOMES PEGO ${ }^{4}$
}

\begin{abstract}
RESUMO - São denominadas "Sempre-vivas" diversas plantas da família Eriocaulaceae, nativas dos campos rupestres de Minas Gerais e da Bahia, sendo utilizados seus capítulos e escapos para fins de decoração. Dentre as espécies exploradas comercialmente, destaca-se a Syngonanthus elegans (Bong) Ruhland, conhecida como sempre-viva pé-de-ouro e, por tal motivo, é uma das espécies com maior perigo de extinção. O objetivo nesta pesquisa foi avaliar o efeito da época de colheita, da irrigação e da permanência de sementes em solo seco no desenvolvimento inicial de plântulas de sempre-viva (Syngonanthus elegans (Bong.) Ruhland). Capítulos de S. elegans foram colhidos manualmente em seis épocas (20/05/06, 21/06/06, 28/07/06, 29/08/06, 20/09/06 e 20/10/06) em local de ocorrência natural dentro do Campus II da UFVJM em um Neossolo Quartzarênico Hidromórfico típico e, posteriormente, submetidos a testes para avaliação do vigor e da germinação das sementes (Experimento 1). As sementes de cada época de colheita foram semeadas superficialmente em copos plásticos (um capítulo em cada copo), contendo o solo original e irrigadas com água destilada todos os dias e a cada dois dias, quatro dias, seis dias e oito dias, por um período de sessenta dias. Fez-se a contagem das plântulas emergidas em cada copo aos quarenta e sessenta dias do início da semeadura (Experimento 2). Sementes colhidas em 21/06/06 também foram semeadas superficialmente em copos plásticos (um capítulo em cada copo) em solo seco, permanecendo por trinta dias, sessenta dias e noventa dias nesta condição e, após, irrigados todos os dias. Procedeu-se a contagem das plântulas emergidas em cada copo aos quarenta e sessenta dias do início da irrigação (Experimento 3). O delineamento experimental utilizado foi o inteiramente casualizado (IC), para os Experimentos 1 e 3 e IC no esquema fatorial 5 x 6 (períodos de irrigação x épocas de colheita) para o Experimento 2, com seis repetições. A melhor qualidade fisiológica de sementes de S. elegans foi obtida nas colheitas realizadas em 28/07/06 e 29/08/06. Intervalos de irrigação de dois ou mais dias afetaram negativamente a emergência das plântulas de S. elegans. A permanência por noventa dias em solo seco melhorou a qualidade fisiológica das sementes.
\end{abstract}

Termos para indexação: vigor, germinação, emergência.

\section{EFFECT OF THE CROP TIME, IRRIGATION AND DRY SOIL SEEDS PERMANENCE IN THE INITIAL DEVELOPMENT OF Syngonanthus elegans (Bong.) Ruhland ${ }^{1}$}

ABSTRACT - Star-flowers are as several plants of the Eriocaulaceae family, native of the fields rupestres of Minas Gerais and of Bahia, being used their capitulum and escape for decoration ends.

${ }^{1}$ Submetido em 02/05/2007 . Aceito para publicação em 28/02/2008.

${ }^{2}$ Eng. Agro., D.S., Prof. Adjunto, Departamento de Agronomia - UFVJM, Caixa Postal 38, CEP 39100-000. Diamantina, MG., e-mail: russinunes@, yahoo.com.br.

${ }^{3}$ Mestrandas do Programa de Pós-Graduação em Produção Vegetal -
UFVJM, Caixa Postal 38, CEP 39100-000. Diamantina, MG., e-mail: spaslauski@yahoo.com.br; path2233@yahoo.com.br

${ }^{4}$ Aluno de Graduação do Curso de Agronomia - UFVJM, Caixa Postal 38, CEP 39100-000, Diamantina, MG., e-mail: engagropego@yahoo.com.br. 


\begin{abstract}
Among the species explored commercially, she stands out the Syngonanthus elegans (Bong) Ruhland, known as star-flower foot-of-gold and, for such a reason, it is one of the species with larger extinction danger. The objective in this research was to evaluate the effect of the crop time, of the irrigation and dry soil seeds permanence in the initial development of Syngonanthus elegans (Bong.) Ruhland). . Capitulum of S. elegans were picked manually in six times (20/05/06, 21/06/06, 28/07/06, 29/08/06, 20/09/06 and 20/10/06) in place of natural occurrence inside of the Campus II of UFVJM in a Neossolo Quartzarênico Hidromórfico típico and, later, were submitted to vigor and germination tests (Experiment 1). The seeds of each crop time were sowed superficially in plastic glasses (one chapter in each glass), containing the original soil and irrigated with distilled water everyday, every two day, four days, six days and eight days, for a period of sixty days. It was made the counting of the emerged plants in each glass to the forty and sixty days of the beginning of the sowing (Experiment 2). Seeds picked in 21/06/06 were sowed also superficially in plastic glasses (one capitulo in each glass) in dry soil, staying for thirty days, sixty days and ninety days in this condition and, after, irrigated everyday. It was made the counting of the emerged plants in each glass to the forty and sixty days of the beginning of the irrigation (Experiment 3). Used a entirely randomized design for the Experiments 1 and 3 and entirely randomized design in the factorial outline $5 \times 6$ (irrigation periods $\mathrm{x}$ crop times) for the Experiment 2, with six repetitions. The best physiological quality seeds of S. elegans was obtained in the crops accomplished in 28/07/06 and 29/08/06. Intervals of irrigation of two or more days affected the emergency of the plants of S. elegans negatively. The permanence for ninety days in dry soil improved the physiological quality seeds.
\end{abstract}

Index terms: .vigor, germination, emergence.

\section{INTRODUÇÃO}

Syngonanthus elegans (Bong.) Ruhland pertence à família Eriocaulácea e ocorre nos campos rupestres do Brasil, principalmente na região de Diamantina-MG que pertence à Cadeia do Espinhaço e se estende nos Estados de Minas Gerais e Bahia (Scatena et al., 1996).

Também conhecida vulgarmente pelo nome de sempreviva pé-de-ouro é considerada a mais importante dentre as espécies de sempre-vivas pelo seu alto valor comercial. Essa flores, depois de colhidas e secas, são utilizadas em artigos de decoração e distribuídas para todo Brasil, além de serem exportadas para vários países do mundo. A coleta destes tipos de flores constitui a principal fonte de renda para muitas comunidades da região, quando não a única (Giulietti et al., 1988).

A cidade de Diamantina é o maior pólo de produção e comercialização de sempre-vivas de primeira qualidade (próprias para exportação) e o maior centro de diversidade de espécies do país.

Porém, a produção de sempre-vivas vem decrescendo consideravelmente no decorrer dos anos, devido principalmente à colheita de modo extrativista, sem considerar questões ecológicas e de manejo cultural. Espécies de sempre-vivas estão sendo extintas de seu ambiente natural
(Mendonça e Lins, 2000) e colocando em risco a diversidade da flora, podendo resultar no encerramento dessa alternativa de exploração.

Guilietti et al. (1987) consideraram S. elegans como uma espécie que apresentou grande redução nas áreas de ocorrência e hoje apresenta sérios riscos de extinção.

Pelo fato de $S$. elegans se tratar de espécie ornamental economicamente viável, e que pode vir a ser cultivada, é necessário conhecer melhor os aspectos agronômicos que norteiam a produção dessas plantas. Informações como a época de produção e colheita das sementes, necessidades hídricas e comportamento no armazenamento são importantes para o conhecimento do hábito dessa espécie e servem de base para o desenvolvimento de estratégias de manejo e multiplicação.

O objetivo nesta pesquisa foi avaliar o efeito da época de colheita, da irrigação e da permanência de sementes em solo seco no desenvolvimento inicial de plântulas de sempre-viva (Syngonanthus elegans (Bong.) Ruhland).

\section{MATERIAL E MÉTODOS}

Experimento 1 - Capítulos de $S$. elegans foram colhidos manualmente em seis épocas (20/05/06, 21/06/06, 28/07/06, 29/08/06, 20/09/06 e 20/10/06), em área de $500 \mathrm{~m}^{2}$ em local 
de ocorrência natural dentro do Campus II da Universidade Federal dos Vales do Jequitinhonha e Mucuri, em Diamantina,

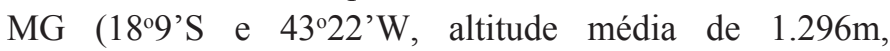
temperatura média anual de $18,1^{\circ} \mathrm{C}$ ). Os dados de temperatura média e precipitações pluviométricas, referentes ao período do trabalho e as médias de precipitação pluviométrica entre 1971 a 1990 foram coletados na Estação Meteorológica de Diamantina (INMET, 2007) e são apresentados na Figura 1.

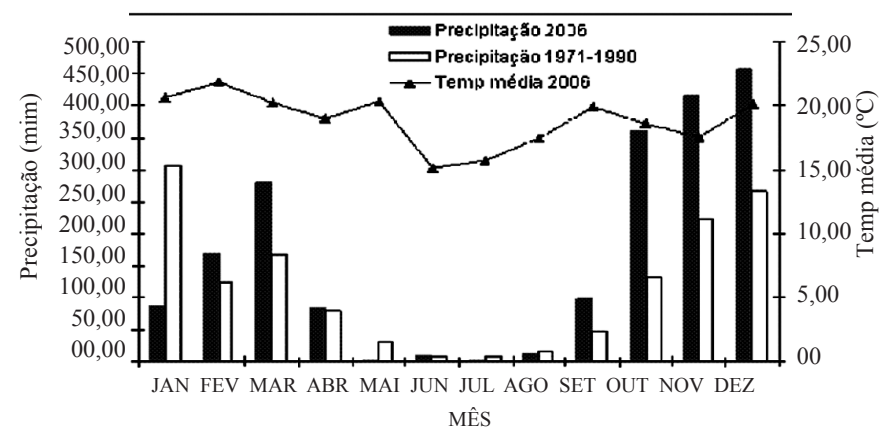

FIGURA 1. Distribuição mensal da precipitação (2006 e 1971 a 1990) e temperatura média durante o período de estudo em Diamantina, MG, 2007.

A área encontra-se próxima à Rodovia BR 367 em um Neossolo Quartzarênico Hidromórfico típico, textura arenosa, ácido, com médios teores de matéria orgânica, e baixos valores de nutrientes, baixa CTC, com significativos teores de $\mathrm{Al}^{3+}$, apresentando afloramento de rochas e relevo plano condicionando o acúmulo de água no solo por grande parte do ano (Embrapa, 2006).

Após a colheita os capítulos apresentavam-se com umidade entre 12 e $13 \%$ sendo, então secados à temperatura ambiente no Laboratório de Sementes (LS) da UFVJM até apresentarem teores de umidade entre 10 e $11 \%$ (base úmida).

Amostras de sementes, correspondendo às épocas de colheita, foram extraídas friccionando-se levemente os capítulos com uma espátula sobre placas de Petri, sendo separadas, posteriormente, com o auxílio de microscópio estereoscópio. Na primeira colheita $(20 / 05 / 06)$ não haviam sementes formadas, o que foi constatado pela observação dos ovários vazios (não fertilizados). Na segunda, terceira, quarta e quinta colheita as sementes já estavam formadas e maduras (tom avermelhado e livres entre sí) e facilmente dispersas quando friccionadas com espátula. $\mathrm{Na}$ última colheita (20/10/06) não havia mais sementes nos capítulos.

Em seqüência, as sementes foram submetidas aos testes para avaliação do vigor e da germinação, utilizando-se a metodologia proposta por Kraus et al. (1996), com adaptação: 150 sementes de cada época de colheita foram colocadas em placas de Petri (seis repetições de 25 sementes), forradas com papel filtro umedecido com água destilada e ensacadas com sacos transparentes de polietileno. Em seguida, as placas de Petri foram levadas para câmara de germinação com 24 horas de luz por dia $\left(30 \mu \mathrm{mol} \cdot \mathrm{m}^{-2} \cdot \mathrm{s}^{-1}\right.$ de iluminância $)$, à $25^{\circ} \mathrm{C}$. A germinação foi avaliada com microscópio estereoscópio, utilizando-se como critério de referência a emergência do eixo embrionário (Oliveira e Garcia, 2005). A germinação constou da percentagem de plântulas normais realizadas em duas contagens. A primeira contagem das plântulas foi realizada com vinte dias e a segunda com quarenta dias do início do teste. Para vigor, foi considerado o registro da percentagem de plântulas normais ocorridas vinte dias após a implantação do teste de germinação.

Experimento 2 - Após cada época de colheita, outra parte dos capítulos foi levada para copos plásticos de $200 \mathrm{~mL}$ contendo o solo original das parcelas e previamente irrigado por vários dias para germinação de possíveis sementes da $S$. elegans e de outras espécies. Em cada copo foi depositado um capítulo sendo as sementes extraídas friccionando-se levemente os capítulos com uma espátula sobre os copos e semeadas superficialmente.

Em cada época de colheita os copos foram irrigados com um pequeno regador, com $5 \mathrm{~mL}$ de água destilada, obedecendo ao seguinte esquema: irrigação todos os dias, irrigação a cada dois dias, a cada quatro dias, seis dias e oito dias, por um período de sessenta dias. A emergência das plântulas originadas de sementes collhidas em todas as épocas deu-se em média aos vinte dias após a semeadura. Após a emergência considerouse mais vinte dias e procedeu-se a contagem das plântulas por capítulo em cada copo (emergência aos quarenta dias após a semeadura). Aos sessenta dias do início da semeadura fez-se a contagem final das plântulas (emergência aos sessenta dias após a semeadura).

Experimento 3 - Em cada copo, preparado conforme descrição anterior foi depositado um capítulo colhido em 21/06/06 e, em seguida, as sementes foram sendo extraídas friccionando-se levemente os capítulos com uma espátula sobre os copos e semeadas superficialmente. Obtiveram-se os seguintes tratamentos: sementes semeadas em solo seco e, em seguida irrigado com $5 \mathrm{~mL}$ de água destilada, todos os dias; sementes semeadas em solo seco e permanecendo por trinta dias, sessenta e noventa dias nesta condição e após irrigado todos os dias. A emergência das plântulas em todos os tratamentos deu-se em média aos vinte dias do início da 
irrigação. Após o início da irrigação em todos os tratamentos consideraram-se mais quarenta dias e procedeu-se a contagem das plântulas por capítulo em cada copo (emergência aos quarenta dias após a irrigação). Aos sessenta dias do início da irrigação fez-se a contagem final das plântulas (emergência aos sessenta dias após a irrigação).

O delineamento experimental utilizado foi o inteiramente casualizado (IC), para os Experimentos 1 e 3 e IC no esquema fatorial $5 \times 6$ (períodos de irrigação x épocas de colheita) para o Experimento 2, com seis repetições. Os dados de vigor e de germinação foram previamente transformados em arco-seno $\sqrt{\% / 100}$ para análise estatística. As comparações entre as médias foram feitas mediante a aplicação do teste de Tukey ao nível de $5 \%$ de probabilidade.

\section{RESULTADOS E DISCUSSÃO}

Experimento 1: Os resultados do vigor e da germinação para as sementes de $S$. elegans colhidas em diferentes épocas estão apresentados na Tabela 1. Observa-se que os valores de vigor não se diferenciaram estatisticamente nas épocas de colheitas. Entretanto, para germinação, os maiores valores foram obtidos quando as colheitas foram realizadas em 28/07/06 e 29/08/06. Os maiores valores obtidos para germinação (24 e 17\%) podem ser considerados baixos quando comparados aos encontrados por Oliveira e Garcia (2005) e Scatena et al. (1996) com percentagens de germinação de $75 \%$ e $80 \%$, respectivamente, portanto, valores muito acima dos encontrados no presente trabalho.

TABELA 1. Vigor e germinação de sementes de $S$. elegans em função das épocas de colheita, Diamantina, MG, 2007.

\begin{tabular}{ccc}
\hline Épocas de colheita & Vigor (\%) & Germinação (\%) \\
\hline $20 / 05 / 06$ & - & - \\
$21 / 06 / 06$ & $1,00 \mathrm{~A}$ & $8,00 \mathrm{~B}$ \\
$28 / 07 / 06$ & $6,00 \mathrm{~A}$ & $24,00 \mathrm{~A}$ \\
$29 / 08 / 06$ & $6,00 \mathrm{~A}$ & $17,00 \mathrm{~A}$ \\
$20 / 09 / 06$ & $1,00 \mathrm{~A}$ & $3,00 \mathrm{~B}$ \\
$20 / 10 / 06$ & - & - \\
\hline CV $(\%)$ & 55 & 50 \\
\hline
\end{tabular}

Médias seguidas pelas mesmas letras nas colunas não diferem entre si pelo teste de Tukey, a $5 \%$ de probabilidade.

A temperatura utilizada no teste de germinação no presente estudo $\left(25^{\circ} \mathrm{C}\right)$ poderia ter influenciado a resposta germinativa das sementes. Entretanto, Scatena et al. (1996) utilizando temperatura de $25^{\circ} \mathrm{C}$ obtiveram percentagem de germinação de $80 \%$. Oliveira e Garcia (2005) comprovaram que a $25^{\circ} \mathrm{C}$ a percentagem de germinação obtida $(72 \%)$ não diferiu das percentagens de germinação nas demais temperaturas utilizadas em seus trabalhos $\left(20\right.$ e $\left.30^{\circ} \mathrm{C}\right)$. Bedê (2002) em pesquisa realizada em São Gonçalo do Rio Preto, MG, obteve taxas de germinação inferiores a $40 \%$ utilizando temperaturas constantes de $15,20,25$ e $30^{\circ} \mathrm{C}$.

È provável que a interação de fatores como local e época em que as sementes foram colhidas e as diferenças de solo, temperatura e umidade encontradas nestes locais, durante o desenvolvimento das plantas e a formação das sementes, tenham influenciado tais resultados. Outros fatores como mudanças na morfologia decorrentes da adaptação aos diferentes microclimas também podem resultar em respostas diferenciadas no desenvolvimento das plantas. Moreira e Camalier (1977) observam que na flora dos campos rupestres existem numerosas adaptações devidas às características do substrato que leva à necessidade de retenção de água em situações extremas. Scatena e Menezes (1996) identificaram em Syngonanthus Ruhl. características anatômicas encontradas nos eixos dos escapos e folhas que representam adaptações a habitats sujeitos a ventos constantes e solos secos ou encharcados, mesmo que temporariamente.

Em colheitas mais tardias (28/07/06 e 29/08/06) em relação à colheita das flores para ornamentação, como observado anteriormente (Tabela 1), foram obtidas sementes com melhor qualidade fisiológica, o que é totalmente desejável, porém, na prática, os colhedores de sempre-viva em Diamantina efetuam as colheitas de flores principalmente nos meses de abril e maio, período em que as flores destacamse pela alvura e é obtido o maior valor comercial das flores (Bedê, 2002). O atraso na colheita e a colheita parcial dos capítulos produzidos pelas plantas poderiam, portanto, ser estratégia aceitável, o que permite a dispersão das sementes antes do arranquio e com possibilidades de permitir a sobrevivência e o estabelecimento das futuras plantas.

Experimento 2: Houve efeito significativo da interação época de colheita $\mathrm{x}$ intervalos de irrigação para a variável emergência das plântulas por capítulo aos quarenta dias (E40) e sessenta dias (E60) após a semeadura (Tabelas 2 e $3)$.

A interação significativa para época de colheita $\mathrm{x}$ intervalos de irrigação para as características E40 e E60 mostra que as melhores épocas de colheita foram àquelas realizadas em 28/07/06 e 29/08/06 para E40 e para E60 em $28 / 07 / 06$, procedendo-se a irrigação todos os dias. O 
maior estabelecimento das plântulas coincide com a maior e 29/08/06 (Tabela 1). germinação verificada nas colheitas realizadas em 28/07/06

TABELA 2. Emergência de plântulas de $S$. elegans (em número de plântulas/capítulo) aos quarenta dias após a semeadura em função das épocas de colheita e intervalos de irrigação, Diamantina, MG, 2007.

\begin{tabular}{cccccc}
\hline Épocas de & \multicolumn{5}{c}{ Intervalos de irrigação } \\
\cline { 2 - 6 } colheita & Todos os dias & A cada dois dias & A cada quatro dias & A cada seis dias & A cada oito dias \\
\hline $20 / 05 / 06$ & - & - & - & - & - \\
$21 / 06 / 06$ & $6,50 \mathrm{Ba}$ & $0 \mathrm{Bb}$ & $0 \mathrm{Ab}$ & $0 \mathrm{Ab}$ & $0 \mathrm{Ab}$ \\
$28 / 07 / 06$ & $14,17 \mathrm{Aa}$ & $7,00 \mathrm{Ab}$ & $0 \mathrm{Ac}$ & $0 \mathrm{Ac}$ & $0 \mathrm{Ac}$ \\
$29 / 08 / 06$ & $12,17 \mathrm{Aa}$ & $7,33 \mathrm{Ab}$ & $0 \mathrm{Ac}$ & $0 \mathrm{Ac}$ & $0 \mathrm{Ac}$ \\
$20 / 09 / 06$ & $3,33 \mathrm{Ba}$ & $1,5 \mathrm{Ba}$ & $0 \mathrm{Aa}$ & $0 \mathrm{Aa}$ & $0 \mathrm{Aa}$ \\
$20 / 10 / 06$ & - & - & - & - & - \\
\hline $\mathrm{CV}(\%)$ & 51,40 & & & & \\
\hline
\end{tabular}

Médias seguidas pelas mesmas letras maiúsculas nas colunas e minúsculas na linha não diferem entre si pelo teste de Tukey, a 5\% de probabilidade.

TABELA3. Emergência de plântulas de $S$. elegans (em número de plântulas/capítulo) aos sessenta dias após a semeadura em função das épocas de colheita e intervalos de irrigação, Diamantina, MG, 2007.

\begin{tabular}{cccccc}
\hline \multirow{2}{*}{$\begin{array}{c}\text { Épocas de } \\
\text { colheita }\end{array}$} & \multicolumn{5}{c}{ Intervalos de irrigação } \\
\cline { 2 - 6 } & Todos os dias & A cada dois dias & A cada quatro dias & A cada seis dias & A cada oito dias \\
\hline $20 / 05 / 06$ & - & - & - & - & - \\
$21 / 06 / 06$ & $12,33 \mathrm{Ba}$ & $0 \mathrm{Bb}$ & $0 \mathrm{Ab}$ & $0 \mathrm{Ab}$ & $0 \mathrm{Ab}$ \\
$28 / 07 / 06$ & $18,17 \mathrm{Aa}$ & $5,8 \mathrm{Ab}$ & $0 \mathrm{Ac}$ & $0 \mathrm{Ac}$ & $0 \mathrm{Ac}$ \\
$29 / 08 / 06$ & $13,50 \mathrm{Ba}$ & $7,33 \mathrm{Ab}$ & $0 \mathrm{Ac}$ & $0 \mathrm{Ac}$ & $0 \mathrm{Ac}$ \\
$20 / 09 / 06$ & $9,17 \mathrm{Ba}$ & $5,17 \mathrm{Aa}$ & $0 \mathrm{Ab}$ & - & - \\
$20 / 10 / 06$ & - & - & - & & - \\
\hline $\mathrm{CV}(\%)$ & 46,53 & & & & \\
\hline
\end{tabular}

Médias seguidas pelas mesmas letras maiúsculas nas colunas e minúsculas na linha não diferem entre si pelo teste de Tukey, a de 5\% de probabilidade.

As plântulas emergiram em maior número quando a irrigação foi efetuada todos os dias, o que ressalta e confirma a adaptação da espécie ao ambiente natural de origem, ou seja, constante umidade no solo por grande parte do ano, não sendo, porém, o ambiente obrigatório para a ocorrência da espécie. Parra (1998) enfatiza que $S$. elegans apresenta grandes populações e ampla área de distribuição, desde Diamantina até a Serra do Cipó. Scatena et al. (1999) relatam que espécies de Syngonanthus crescem em diferentes condições edáficas, habitando solos secos, úmidos e até alagados e sempre expostas ao sol.

Pelos resultados mostrados nas Tabelas 2 e 3 fica evidente a sensibilidade à falta de umidade no solo na emergência das plântulas com intervalos de irrigação de dois ou mais dias, provavelmente devido à baixa disponibilidade de água no solo e insuficiente para permitir o processo germinativo.

Diante disso, é imprescindível a observação da melhor época de colheita visando obter sementes com melhor qualidade fisiológica e, portanto, com melhor desempenho em condições de campo. O manejo da irrigação, como turnos e intervalos de molhamento das áreas para produção de sementes, também deverá ser realizado.

Experimento 3: O efeito do tempo de armazenamento das sementes em solo seco na E40 e E60 encontra-se na Tabela 4. A emergência de plântulas aumentou com o tempo de armazenamento em solo seco para E40 e E60. Os maiores valores foram obtidos a partir de trinta dias de armazenamento em solo seco, com irrigação todos os dias após esse período, em E40 e após sessenta e noventa dias em solo seco, com irrigação após esses períodos em E60. 
TABELA 4. Emergência de plântulas de S. elegans (em número de plântulas/capítulo) aos quarenta e sessenta dias do início da irrigação em função do tempo de permanência em solo seco, Diamantina, MG, 2007.

\begin{tabular}{crc}
\hline Tempo de permanência & \multicolumn{2}{c}{ Emergência de plântulas } \\
\cline { 2 - 3 } Em solo seco & 40 DIAS & 60 DIAS \\
\hline Zero & $6,50 \mathrm{~B}$ & $12,33 \mathrm{C}$ \\
30 & $19,00 \mathrm{~A}$ & $19,16 \mathrm{BC}$ \\
60 & $26,30 \mathrm{~A}$ & $27,16 \mathrm{AB}$ \\
90 & $22,66 \mathrm{~A}$ & $41,50 \mathrm{~A}$ \\
MÉDIA & 18,61 & 25,03 \\
\hline CV $(\%)$ & 60,63 & 50,00 \\
\hline
\end{tabular}

Médias seguidas pelas mesmas letras maiúsculas nas colunas não diferem entre si pelo teste de Tukey, a de 5\% de probabilidade.

Pelos resultados encontrados constata-se que as sementes requerem um período de pós-maturação, concordando com Sá Carvalho e Ribeiro (1994), possivelmente para inibição de algum mecanismo de impedimento à germinação. Segundo Paixão-Santos et al. (2003) a observação da morfologia de S. mucugensis conduz à idéia da não existência de tegumento endurecido nas sementes, entretanto, devido a dificuldade de germinação da espécie é provável a existência de camada impermeável que impossibilita a embebição das sementes.

Os colhedores de sempre-viva em Diamantina realizam a colheita dos escapos florais nos meses de abril e maio e, após os trabalhos de secagem, limpeza e seleção para exportação, o material descartado, constituído de escapos e capítulos pequenos é armazenado para semeadura na época das águas. Em geral as inflorescências são moídas em picadeiras e o macerado é lançado ao solo antes do início da estação chuvosa. Os locais escolhidos para os plantios incluem aqueles onde a planta já existia naturalmente e teve suas populações diminuídas e outros terrenos planos e facilmente irrigáveis, com ou sem a formação de canteiros.

As informações de técnicas para exploração da sempreviva, principalmente $S$. elegans, como épocas de colheita de sementes e plantio, armazenamento, manejo da irrigação, entre outras, são escassas e muito variáveis. Não existem estudos para determinar as épocas de colheita que irão originar sementes com boa qualidade fisiológica, assim como resultados do comportamento das sementes sob armazenamento.

Dessa forma, considerando a grande importância que representa para Diamantina o trabalho com sempre-vivas, mais pesquisas devem ser realizadas, imprescindíveis para o desenvolvimento de práticas seguras e embasadas em princípios ecológicos que garantirão a sobrevivência da espécie e a continuidade dessa atividade comercial.

\section{CONCLUSÕES}

A melhor qualidade fisiológica de sementes de $S$. elegans é obtida em colheitas realizadas nos meses de julho e agosto na região de Diamantina, quando apresentam tom avermelhado e se dispersam com facilidade.

Intervalos de irrigação de dois ou mais dias afetaram negativamente a emergência das plântulas de S. elegans.

A permanência das sementes por ate noventa dias em solo seco melhora a qualidade fisiológica das sementes.

\section{REFERÊNCIAS}

BEDÊ, L.C. Busca de alternativas para uso sustentado de sempre-vivas na região de Diamantina, MG: Estudo dos efeitos decorrentes do manejo extrativista sobre a dinâmica populacional de Syngonanthus elegans var. elenatus (Eriocaulaceae). Belo Horizonte: UFMG, 2002. 17p. (Instituto de Ciências Biológicas. Relatório Técnico).

EMBRAPA. Centro Nacional de Pesquisas de Solos. Sistema Brasileiro de Classificação de Solos. Rio de Janeiro: Embrapa Solos, EMBRAPA Produção de Informação, 2006. $306 \mathrm{p}$.

GIULIETTI, N.; GIULIETTI, A.M.; PIRANI, J.R.; MENEZES, N.L. Estudos de sempre-vivas: importância econômica do extrativismo em Minas Gerais, Brasil. Acta Botanica Brasílica, v.1, n.2, p.179-192, 1988.

GIULIETTI, A.M.; MENEZES, N.L.; PIRANI, J.R.; MEGURO, M.; WANDERLEY, M.G.L. Flora da serra do cipó, Minas Gerais; caracterização e lista de espécies. Boletim de Botânica da Universidade de São Paulo, v.9, p.1-151, 1987.

INSTITUTONACIONALDEMETEOROLOGIA(INMET).

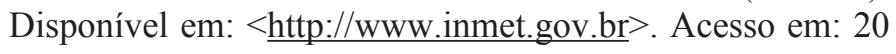


abr. 2007.

KRAUS, J.E; SCATENA, V.L.; LEWINGER, M.E.; TRENCH, K.U. Morfologia externa e interna de quatro espécies de Paepalanthus Kunth (Eriocaulaceae) em desenvolvimento pós-seminal. Boletim de Botânica da Universidade de São Paulo, v.15, p.45-53, 1996.

MENDONÇA, M.P.; LINS, L.V. Lista vermelha das espécies ameaçadas de extinção da flora de Minas Gerais. Belo Horizonte: Fundação Biodiversitas/ Fundação ZooBotânica de Belo Horizonte, 2000.

MOREIRA, A.A.N.; CAMALIER, C. Relevo. In: GEOGRAFIA do Brasil. Região Sudeste. Rio de Janeiro: IBGE. v.3, p.1-50, 1977.

OLIVEIRA, P.G.; GARCIA, Q.S. Efeitos da luz e da temperatura na germinação de sementes de Syngonanthus elegantulus Ruhland, S. elegans (Bong.) Ruhland e $S$. venustus Silveira (Eriocaulaceae). Acta Botanica Brasílica, v.19, n.3, p.639-645, 2005.

PAIXÃO-SANTOS, J. Da; DORNELLES, A.L.C; SILVA, J.R.Dos.S.; RIOS, A.P. Germinação in vitro de Syngonanthus mucugensis Giulietti. Sitientibus série Ciência Biológicas, v.3, n.1/2, p.120-124, 2003.

PARRA, J.R. Flora da Serra do Cipó, Minas Gerais: Syngonanthus Ruhland (Eriocaulaceae). Boletim de Botânica da Universidade de São Paulo, v.17, p.219-252, 1998.

SÁ e CARVALHO, C.G.; RIBEIRO, M.C. Efeitos do armazenamento e de reguladores de crescimento na germinação de Paepalanthus speciosus, Eriocaulaceae. Revista Brasileira de Botânica, v.17, n.1, p.61-65, 1994.

SCATENA, V.L.; CARDOSO, V.A.; GIULIETTI, A.M. Morfoanatomia de espécies de Blastocaulon Ruhland (Eriocaulaceae). Acta Botanica Brasílica, v.13, p.29-41, 1999.

SCATENA, V.L.; LEMOS FILHO, J.P.; LIMA, A.A.A. Morfologia do desenvolvimento pós-seminal de Syngonanthus elegans e S. niveus (Eriocaulaceae). Acta Botanica Brasílica, v.10, p.85-91, 1996.

SCATENA, V.L.; MENEZES, N.L. Anatomia dos escapos e folhas de Syngonanthus Ruhl. (Eriocaulaceae). Revista Brasileira de Biologia, v.56, n.2, p.317-332, 1996. 